\title{
The association of endothelin-1 gene polymorphism and its plasma levels with hypertension and coronary atherosclerosis
}

\author{
Nazanin Ebrahimi ${ }^{1}$, Gholamreza Asadikaram ${ }^{2}$, Abbas Mohammadi $^{3}$, Yunes Jahani ${ }^{4,5}$, Mina Moridi ${ }^{6}$, \\ Mohammad Masoumi ${ }^{7}$
}

\begin{abstract}
${ }^{1}$ Physiology Research Center, Institute of Basic and Clinical Physiology Sciences, Kerman University of Medical Sciences, Kerman, Iran

${ }^{2}$ Neuroscience Research Center, Institute of Neuropharmacology, Kerman University of Medical Sciences, Kerman, Iran

${ }^{3}$ Endocrinology and Metabolism Research Center, Institute of Basic and Clinical

Physiology Sciences and Department of Biochemistry, Afzalipur Faculty of Medicine, Kerman University of Medical Sciences, Kerman, Iran

${ }^{4}$ Modeling in Health Research Center, Institute for Futures Studies in Health,

Kerman University of Medical Sciences, Kerman, Iran

${ }^{5}$ Department of Biostatistics and Epidemiology, School of Public Health,

Kerman University of Medical Sciences, Kerman, Iran

${ }^{6}$ Cardiovascular Research Center, Institute of Basic and Clinical Physiology Sciences, Kerman University of Medical Sciences, Kerman, Iran

${ }^{7}$ Department of Cardiology And Cardiovascular Research Center, Faculty of Medicine, Kerman University of Medical Science, Kerman, Iran
\end{abstract}

Submitted: 21 January 2018; Accepted: 25 May 2018;

Online publication: 22 July 2019

Arch Med Sci 2021; 17 (3): 613-620

DOI: https://doi.org/10.5114/aoms.2019.86770

Copyright (c) 2019 Termedia \& Banach

\section{Abstract}

Introduction: Endothelin-1 (ET-1) is the most potent among all vasoconstrictors, and its association with cardiovascular diseases has been reported before. Our aim was to investigate the association of ET-1 plasma level and its gene polymorphisms (rs5370 and rs10478694) with hypertension and coronary atherosclerosis (CA).

Material and methods: This study was carried out on 128 women and 132 men, who were divided into 4 groups: hypertensive without atherosclerosis $(\mathrm{H}+\mathrm{A}-)$; hypertensive with atherosclerosis $(\mathrm{H}+\mathrm{A}+)$; non-hypertensive with atherosclerosis $(\mathrm{H}-\mathrm{A}+$ ); and non-hypertensive without atherosclerosis (control group). Endothelin-1 plasma levels were measured by ELISA, and gene polymorphisms were detected by polymerase chain reaction - restriction fragment length polymorphism (PCR-RFLP) methods. Coronary artery diseases (CAD) were then defined based on angiography data.

Results: The ET-1 plasma level was significantly higher in the $\mathrm{H}+\mathrm{A}+$ group in comparison with the other groups, especially $\mathrm{H}+\mathrm{A}-$. Comparing people with CA and those without it, the highest frequency level of the T allele of rs5370 was found in people with CA. Significantly higher frequencies of the $3 \mathrm{~A}$ allele were detected in hypertensive patients in comparison with non-hypertensive individuals, when analyzing rs 10478694.

Conclusions: Endothelin-1 plasma level shows a direct association with the risk of CA development. The T allele of rs5370 can be regarded as a risk factor for CA development. The 3A allele of rs 10478694 can be associated with the risk of hypertension; therefore, it can be concluded that ET-1 and its gene polymorphisms play an important role in CA development and hypertension observed in the south-eastern populations of Iran.

\author{
Corresponding authors: \\ Gholamreza Asadikaram PhD \\ Neuroscience Research Center \\ Institute of \\ Neuropharmacology and \\ Department of Biochemistry \\ Afzalipur Faculty of Medicine \\ Kerman University \\ of Medical Sciences \\ Kerman, Iran \\ E-mail: gh_asadi@kmu.ac.ir
}

Mohammad Masoumi Department of Cardiology Faculty of Medicine and Cardiovascular Research Center Kerman University of Medical Science Kerman, Iran E-mail: masoomidr@yahoo. com 


\section{Introduction}

The endothelin (ET) family consists of three members, ET-1, ET-2 and ET-3 [1], among which ET-1, being the most frequent peptide in blood vessels, is the most salient of all. Endothelin-1 contains 21 amino acids and two disulfide bonds and its biosynthesis is a multi-step process in which the mature form of ET-1 is produced from endothelin converting enzyme (ECE) activity. The ET-1 precursor has 212 amino acids [2]. Endothelin-1 can perform vasoconstriction by binding to two receptors: ETA and ETB [3]. The endothelin system has been known to participate in the pathophysiology of many diseases such as hypertension, atherosclerosis, coronary artery disease (CAD) and heart failure [1].

\section{Endothelin-1 and hypertension}

Hypertension is a health issue increasing constantly worldwide [4], and is a well-known factor leading to cardiovascular diseases [5]. Hypertensive individuals are believed to constitute a quarter of the global adult population, and it is estimated that this proportion will increase to $30 \%$ by 2025 [6]. It has been proposed that endothelin-1, as a potent vasoconstrictor, may have an effective role in some types of hypertension [7]. Ergul et al. found an association between ET-1 and hypertension in the Afro-Caribbean race [8]. This association was also reported in patients with specific conditions such as obesity and insulin resistance $[9,10]$. Asia is the most populated region and there have been numerous reports regarding the increasing risk of cardiovascular diseases in this area [3]. Iran, as an Asian country, is facing the above-mentioned risk as it has been estimated that $46 \%$ (12 million) of Iranians aged between 25 to 64 years are currently suffering from hypertension [11]. Many studies confirm the role of ET-1 in regulating the vascular tone and hypertension [7, 12, 13]; yet, this is a controversial matter [14]. Several types of single nucleotide polymorphisms (SNPs) for the ET-1 gene have been reported so far [15], two of which have been considered to be most closely associated with the pathophysiology of cardiovascular diseases rs5370 and rs10478694.

\section{rs5370}

The rs5370 SNP contains (G/T) substitution and (Lys/Asn) conversion in codon 198 of exon 5 of ET-1 and there are some presumptions regarding its role in hypertension [14]. Genotypes are GG for the wild type, TT for the mutant and GT for heterozygotes [16]. Previous studies have produced controversial results regarding the effect of this SNP on the development of hypertension. Several studies have shown the association of rs5370 with essential hypertension [17]; however, some researchers have reported no association between the distribution of the genotypes of this SNP and the development of hypertension [18]. Tiret along with some other researchers have claimed that this association can be dependent on the body mass index (BMI) $[8,19]$, while a cohort study in the UK did not confirm that [18].

\section{rs 10478694}

According to NCBI this is a kind of indel variation on human chromosome 6 [15], while some studies have referred to it as an SNP of human ET-1 gene [20, 21]. This SNP contains an adenine insertion at position +138 , $5^{\prime}$ untranslated region (UTR) and exon 1 of the ET-1 [22]. The genotypes are as follows: the mutant form (4A/4A), wild type $(3 A / 3 A)$ and the heterozygote $(3 A / 4 A)$ [17]. Some studies have reported increased plasma levels of ET-1 in individuals who have a mutant genotype [17]. Studies have reported different allele distributions among patients with pulmonary artery hypertension (PAH), idiopathic pulmonary artery hypertension (IPAH) and coronary heart disease (CHD), with the control group [23]. They showed a significant increase of alleles containing the $3 \mathrm{~A}$ form in patients with hypertension [23]. Some researchers have shown that there is no significant association between this SNP and the development of hypertension [24, 25].

\section{Endothelin-1 and coronary atherosclerosis}

Coronary artery disease is the major risk factor for myocardial infarction (MI) and heart attack. People with a high cholesterol level and high blood pressure are more prone to develop CAD due to the intima stiffness caused by atherosclerosis $[26,27]$. Atherosclerosis is the main cause of cardiovascular diseases [28] and almost 50\% of the etiology could be explained by major risk factors of atherosclerosis [29]. Lerman et al. detected upregulation of ET-1 in coronary atherosclerosis (CA) $[30,31]$. Endothelin-1 vasoconstriction and the myogenic effect on smooth muscle cells (SMCs) may have an effect on the development of atherosclerotic lesions [32, 33]. On the other hand, some studies have reported no significant association between ET-1 plasma level and the development of atherosclerosis [34]. Therefore, due to the considerable number of controversial reports, the present study aimed to investigate the association between ET-1 plasma level and the development of hypertension and CA in a population located in the south-eastern area of Iran. Also, rs5370 and rs10478694 polymorphisms of the ET-1 gene with hypertension and CA in the considered population. 


\section{Material and methods}

This was a cross-sectional study that involved 260 individuals: 128 women and 132 men with the mean age of $56 \pm 10.05$ years and mean body mass index (BMI) level of $25 \pm 4.9$ with suspected cardiovascular diseases (CVD). Patients were candidates for coronary angiography at Shafa Hospital of Kerman, Iran. These participants were under CAD treatment before coronary angiography, they were symptomatic and had a history of hospitalization in coronary care unit (CCU), or some evidence of having myocardial ischemia.

The study has been approved by the research ethical committee of Kerman University of Medical Sciences (approval number: IR.KMU.REC/93/268).

All patients entered the study voluntarily, filling out the written consent form. All the participants underwent clinical and laboratory evaluation, including a complete medical history and physical examination, measurement of systolic and diastolic blood pressure, a complete blood count (CBC), fasting blood sugar (FBS) and a lipid profile. Clinical blood pressure recordings were performed according to the standard technique using a mercury sphygmomanometer [35]. Hypertension was defined as having a systolic blood pressure higher than $140 \mathrm{~mm} \mathrm{Hg}$ and a diastolic blood pressure more than $90 \mathrm{~mm} \mathrm{Hg}$, or having records of taking any kind of anti-hypertension remedy $[28,36,37]$. Obesity was diagnosed based on the BMI level $>30 \mathrm{~kg} / \mathrm{m}^{2}$ [38]. The presence of coronary atherosclerosis was identified by angiography and ascertained by a qualified cardiologist (angiography was done for all participants). Coronary artery disease was defined as $\geq 50 \%$ luminal diameters stenosis in $\geq 1$ epicardial coronary artery and patients without any plaque and no intimal irregularity were placed in one group and regarded as normal according to angiographic data [39]. Then, all participants were divided into 4 main groups as follows: hypertensive without atherosclerosis ( $\mathrm{H}+\mathrm{A}-$ ) (including 35 women and 26 men); hypertensive with atherosclerosis $(\mathrm{H}+\mathrm{A}+)$ (including 39 women and 37 men); non-hypertensive with atherosclerosis $(\mathrm{H}-\mathrm{A}+$ ) (including 20 women and 41 men); and non-hypertensive without atherosclerosis (the control group) (including 34 women and 28 men). In order to check the allele and genotype distributions, we considered another grouping as follows: hypertensive $(\mathrm{H}+\mathrm{A}+$ and $\mathrm{H}+\mathrm{A}-)$; non-hypertensive $(\mathrm{H}-\mathrm{A}+$ and $\mathrm{H}-\mathrm{A}-)$; individuals with $\mathrm{CAD}(\mathrm{H}-\mathrm{A}+$ and $\mathrm{H}+\mathrm{A}+)$; and individuals without $\mathrm{CAD}(\mathrm{H}-\mathrm{A}-$ and $\mathrm{H}+\mathrm{A}-)$. A $10 \mathrm{ml}$ peripheral blood sample was collected in vials containing ethylenediaminetetraacetic acid (EDTA) from the participants when fasting, and after 7 min of centrifugation at a rate of 2500 revolutions per minute (rpm), plasma samples were collected in separated vials and kept at $-20^{\circ} \mathrm{C}$. DNA extraction was done using peripheral blood lymphocytes based on the "salting out" method [40].

\section{rs5370: polymerase chain reaction - restriction fragment length polymorphism (PCR-RFLP)}

Polymerase chain reaction (PCR) was processed (Corbett Research thermocycler) using the following primers based on a previous study on ET-1 [41]. Forward: 5'-TCTTGCTTTATTAGGTCGGAGACC-3', reverse: 5'-TTTGAACGAGGACGCTGGTC-3'. Cycle conditions were as follows: initial denaturation $95^{\circ} \mathrm{C}$ for $5 \mathrm{~min}, 35$ cycles of $95^{\circ} \mathrm{C}$ for $45 \mathrm{~s}, 59^{\circ} \mathrm{C}$ for $50 \mathrm{~s}, 72^{\circ} \mathrm{C}$ for $45 \mathrm{~s}$, and finally $72^{\circ} \mathrm{C}$ for $10 \mathrm{~min}$ for a final extension. PCR product was a 262 base pair (bp) fragment which was incubated for $16 \mathrm{~h}$ in $37^{\circ} \mathrm{C}$ with restriction enzyme Cac8i (New England Biolabs) and the digested products were electrophoresed in $1.5 \%$ agarose gel.

\section{rs 10478694: PCR-RFLP}

Primers were designed using Vector-NTI version 11.5 - forward: 5'-TCTTGCTTTATTAGGTCGGAGACC-3, reverse: 5'-TTTGAACGAGGACGCTGGTC-3'. Cycle conditions were as follows: initial denaturation $95^{\circ} \mathrm{C}$ for $5 \mathrm{~min}, 35$ cycles of $95^{\circ} \mathrm{C}$ for $45 \mathrm{~s}, 52^{\circ} \mathrm{C}$ for $50 \mathrm{~s}$, $72^{\circ} \mathrm{C}$ for $50 \mathrm{~s}$, and finally $72^{\circ} \mathrm{C}$ for $10 \mathrm{~min}$ for a final extension. The polymerase chain reaction product was a 262 bp fragment which was incubated for an hour at $55^{\circ} \mathrm{C}$ with the restriction enzyme Bsl1 (New England Biolabs) and the digested products were electrophoresed in $1.5 \%$ agarose gel.

\section{Endothelin-1 measurement}

Endothelin-1 of all participants was measured using enzyme linked immunosorbent assay (ELISA) Kit (R\&D systems, Pan specific DuoSet DY1160), and measurement was carried out according to the manufacturer's protocol.

\section{Statistical analysis}

All data for continuous variables are shown as mean \pm standard deviation $(M \pm S D)$ and categorical variables are presented as frequency (percentages). The qualitative variables of the four groups were compared using the $\chi^{2}$ test (or Fisher's exact test) and quantitative variables were compared using one-way ANOVA. The ET-1 plasma level of the four groups was compared by ANCOVA test. By use of Fisher's exact test, the genotype and allele distributions between the hypertensive and non-hypertensive groups were compared and also the same comparison was made between people with coronary atherosclerosis and people without coronary atherosclerosis. Hardy-Weinberg 
equilibrium (HWE) for each polymorphism was assessed by $\chi^{2}$ test. The association of ET- 1 plasma level and CAD was investigated by Pearson's correlation coefficient. Statistical analysis was performed using SPSS version 22 (IBM Corp., Armonk, NY, US).

$P$-values less than 0.05 were considered statistically significant.

\section{Results}

Table I summarizes participants' quantitative and qualitative characteristics. The average age among members of the $\mathrm{H}+\mathrm{A}+$ group was significantly higher than that of the other groups ( $p=$ 0.006). The frequency of women in groups $\mathrm{H}-\mathrm{A}+$ and $\mathrm{H}+\mathrm{A}+$ was significantly higher than in the oth-

Table I. Comparison of qualitative and quantitative variables among the four groups under investigation

\begin{tabular}{|c|c|c|c|c|c|c|}
\hline \multicolumn{2}{|l|}{ Parameter } & $\begin{array}{c}\mathrm{H}-\mathrm{A}- \\
(N=62)\end{array}$ & $\begin{array}{c}\mathrm{H}+\mathrm{A}- \\
(N=61)\end{array}$ & $\begin{array}{c}\mathrm{H}-\mathrm{A}+ \\
(N=61)\end{array}$ & $\begin{array}{c}\mathrm{H}+\mathrm{A}+ \\
(N=76)\end{array}$ & $\begin{array}{l}\text { Statistical } \\
\text { results }\end{array}$ \\
\hline \multirow[t]{2}{*}{ Gender } & Female & $20(32.5)^{\star}$ & $21(35.0)$ & $44(72.0)$ & $43(57.5)$ & \multirow{2}{*}{$\begin{array}{l}\chi^{2}=17.5 \\
p<0.001\end{array}$} \\
\hline & Male & $26(42.5)$ & $16(27.5)$ & $39(65.0)$ & $51(67.5)$ & \\
\hline \multirow{3}{*}{$\begin{array}{l}\text { Angiography } \\
\text { information }\end{array}$} & None & $62(100)$ & $61(100)$ & $13(22.5)$ & $19(25)$ & \multirow{3}{*}{$\begin{aligned} \chi^{2} & =100.2 \\
p & <0.001\end{aligned}$} \\
\hline & 1 vessel & $0(0)$ & $0(0)$ & $20(32.5)$ & $30(40)$ & \\
\hline & $\begin{array}{l}2 \text { or more } \\
\text { vessels }\end{array}$ & $0(0)$ & $0(0)$ & $27(45)$ & $26(35)$ & \\
\hline \multirow[t]{3}{*}{ Addiction } & Cigarettes & $7(12.5)$ & $7(12.5)$ & $13(22.5)$ & $13.3(17.5)$ & $\begin{array}{l}\chi^{2}=2.02 \\
p=0.574\end{array}$ \\
\hline & Opium & $7(12.5)$ & $6(10)$ & $15(25)$ & $11(15)$ & $\begin{array}{l}\chi^{2}=3.93 \\
p=0.202\end{array}$ \\
\hline & Others & $1(2.5)$ & $1(2.5)$ & $4(7.5)$ & $2(2.5)$ & $\begin{array}{l}\chi^{2}=2.08 \\
p=0.551\end{array}$ \\
\hline \multicolumn{2}{|l|}{ Age [years] } & $52.33 \pm 9.93^{* *}$ & $54.68 \pm 8.68$ & $57.30 \pm 9.05$ & $59.75 \pm 11.19$ & $\begin{array}{l}F=4.354 \\
p=0.006\end{array}$ \\
\hline \multicolumn{2}{|l|}{ BMI $\left[\mathrm{kg} / \mathrm{m}^{2}\right]$} & $25.0 \pm 4.87$ & $26.68 \pm 5.65$ & $24.11 \pm 4.25$ & $24.37 \pm 4.48$ & $\begin{array}{c}F=2.27 \\
p=0.822\end{array}$ \\
\hline \multicolumn{2}{|l|}{$\mathrm{FBS}[\mathrm{mg} / \mathrm{dl}]$} & $92.93 \pm 11.05$ & $94.38 \pm 10.26$ & $93.08 \pm 10.71$ & $92.23 \pm 9.74$ & $\begin{array}{c}F=0.29 \\
p=0.822\end{array}$ \\
\hline \multicolumn{2}{|c|}{ Cholesterol [mg/dl] } & $155.28 \pm 41.24$ & $151.98 \pm 32.77$ & $149.20 \pm 37.39$ & $144.63 \pm 44.72$ & $\begin{array}{c}F=0.52 \\
p=0.662\end{array}$ \\
\hline \multicolumn{2}{|l|}{ TG [mg/dl] } & $153.68 \pm 30.80$ & $170.63 \pm 44.18$ & $157.33 \pm 28.17$ & $175.20 \pm 69.59$ & $\begin{array}{c}F=2.00 \\
p=0.111\end{array}$ \\
\hline \multicolumn{2}{|l|}{$\mathrm{HDL}[\mathrm{mg} / \mathrm{dl}]$} & $40.20 \pm 11.59$ & $38.25 \pm 10.20$ & $36.18 \pm 11.08$ & $37.60 \pm 9.51$ & $\begin{array}{c}F=0.99 \\
p=0.403\end{array}$ \\
\hline \multicolumn{2}{|l|}{ LDL [mg/dl] } & $96.77 \pm 32.62$ & $89.51 \pm 24.57$ & $93.32 \pm 27.60$ & $93.19 \pm 29.83$ & $\begin{array}{c}F=0.42 \\
p=0.732\end{array}$ \\
\hline \multicolumn{2}{|l|}{ Urea [mg/dl] } & $33.75 \pm 13.71$ & $35.98 \pm 10.16$ & $36.60 \pm 11.87$ & $35.28 \pm 10.04$ & $\begin{array}{c}F=0.45 \\
p=0.711\end{array}$ \\
\hline \multicolumn{2}{|c|}{ Creatinine $[\mathrm{mg} / \mathrm{dl}]$} & $1.04 \pm 0.24$ & $.99 \pm 0.24$ & $1.11 \pm 0.21$ & $1.08 \pm 0.23$ & $\begin{array}{c}F=1.92 \\
p=0.131\end{array}$ \\
\hline \multicolumn{2}{|l|}{$\mathrm{Na}[\mathrm{mg} / \mathrm{dl}]$} & $139.50 \pm 3.29$ & $139.70 \pm 3.44$ & $139.95 \pm 2.68$ & $139.90 \pm 3.24$ & $\begin{array}{c}F=0.16 \\
p=0.923\end{array}$ \\
\hline \multicolumn{2}{|l|}{$\mathrm{K}[\mathrm{mg} / \mathrm{dl}]$} & $4.34 \pm 0.36$ & $4.36 \pm 0.46$ & $4.41 \pm 0.43$ & $4.36 \pm 0.42$ & $\begin{array}{c}F=0.18 \\
p=0.911\end{array}$ \\
\hline \multicolumn{2}{|l|}{$\mathrm{SBP}[\mathrm{mm} \mathrm{Hg}]$} & $118.88 \pm 15.38$ & $120.53 \pm 13.34$ & $116.13 \pm 12.58$ & $121.13 \pm 14.52$ & $\begin{array}{c}F=1.02 \\
p=0.381\end{array}$ \\
\hline \multicolumn{2}{|l|}{$\mathrm{DBP}[\mathrm{mm} \mathrm{Hg}]$} & $74.00 \pm 8.49$ & $73.83 \pm 8.06$ & $70.63 \pm 8.18$ & $73.13 \pm 8.98$ & $\begin{array}{c}F=1.45 \\
p=0.232\end{array}$ \\
\hline \multicolumn{2}{|c|}{ Endothelin-1 [pg/ml] } & $5.27 \pm 0.81$ & $4.13 \pm 0.99$ & $7.36 \pm 1.7$ & $9.79 \pm 1.6$ & $\begin{array}{c}F=3.47 \\
p=0.018\end{array}$ \\
\hline
\end{tabular}

The average age among members of the $H+A+$ group was significantly higher than that of the other groups. Averages of the other quantitative variables were not significantly different among the groups. The number of women in groups $H-A+$ and $H+A+$ was significantly higher. Endothelin-1 plasma level was significantly higher in the $H+A+$ group in comparison with the other groups $(p=0.018)$. BMI-body mass index, DBP - diastolic blood pressure, FBS - fasting blood sugar, $H-A--$ no coronary artery disease and no hypertension, $H+A--$ hypertension and no coronary artery disease, $\mathrm{H}-\mathrm{A}+-$ coronary artery disease and no hypertension, $\mathrm{H}+\mathrm{A}_{+}-$coronary artery disease and hypertension, HDL - high-density lipoprotein, LDL - low-density lipoprotein, SBP-systolic blood pressure, TG - triglycerides. 
er groups. Therefore, using the ANCOVA test, ET-1 was compared among the groups with controlled age and gender. The outlier data were identified and excluded using Boxplot. The averages of the other variables were not significantly different among the groups. The genotype and allele frequencies at both SNPS did not confirm the HWE (data not shown).

\section{Endothelin-1 plasma level}

The comparison of plasma ET-1 level among the groups can be generally reported as follows: $\mathrm{H}+\mathrm{A}-$ $<\mathrm{H}-\mathrm{A}-<\mathrm{H}-\mathrm{A}+<\mathrm{H}+\mathrm{A}+(p=0.018)$ (Figure 1). The Tukey results showed a significant difference between ET-1 plasma level in $\mathrm{H}+\mathrm{A}+(4.13 \pm 1.6 \mathrm{pg} / \mathrm{ml})$ and $\mathrm{H}+\mathrm{A}-(9.79 \pm 0.99 \mathrm{pg} / \mathrm{ml})(p=0.018)$.

\section{Frequency of rs5370 and rs 10478694 genotypes and alleles among groups}

When analyzing rs5370, we observed that all four groups contained higher frequencies of GG genotype but comparing the allele and genotype frequencies it was found that the frequency of the T allele $(p=0.003)$ and TT genotype $(p=0.010)$ was significantly higher in people with atherosclerosis than in people without atherosclerosis (Table II).

Analysis of rs10478694 showed significantly higher frequencies of 3A3A genotype $(p=0.007)$ and $3 A$ allele $(p=0.004)$ in hypertensive people in comparison with non-hypertensive individuals (Table III).

No association between ET-1 plasma level and CAD was found $(p=0.625)$. No association between ET-1 plasma level and genotypes in either of the two SNPs were seen $(p=0.332, p=0.102)$.

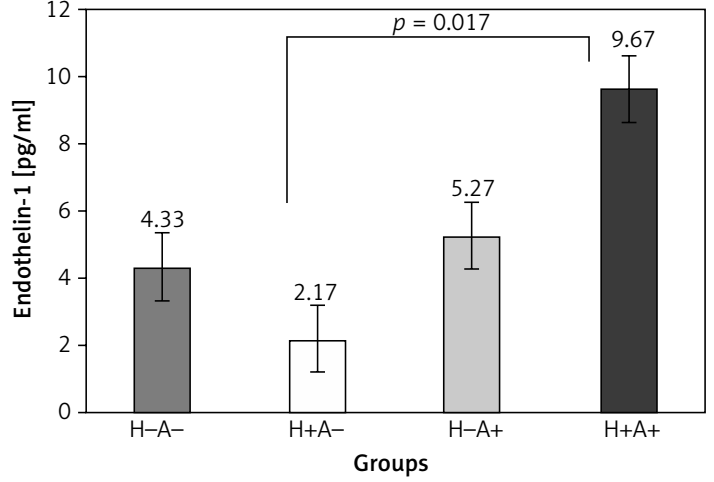

Figure 1. Comparison of endothelin-1 plasma level among the four groups under investigation Endothelin-1 plasma level in the $\mathrm{H}+\mathrm{A}+$ group is significantly higher than in the other groups $(p=0.018)$. Only the difference of endothelin-1 plasma level observed between $\mathrm{H}+\mathrm{A}+$ and $\mathrm{H}+\mathrm{A}-$ is significant ( $p=$ 0.017). $\mathrm{H}+\mathrm{A}--$ hypertension and no coronary artery disease, $\mathrm{H}-\mathrm{A}+-$ coronary artery disease and no hypertension, $\mathrm{H}+\mathrm{A}+-$ coronary artery disease and hypertension, $\mathrm{H}-\mathrm{A}--$ no coronary artery disease and no hypertension. Significant difference at $<0.05$

\section{Discussion}

In this study, we provided evidence that ET-1 plasma level is positively correlated with the risk of CA development. The TT genotype and Asn (T) allele of rs5370 may be associated with the development of CA. The 3A3A genotype and 3A allele of the $r s 10478694$ may be associated with the risk of hypertension.

According to the higher level of plasma ET-1 in the $\mathrm{H}+\mathrm{A}+$ group in comparison with the group $\mathrm{H}+\mathrm{A}-$, we can conclude that ET- 1 is positively associated with the development of atherosclerosis. These findings also confirmed the results of sev-

Table II. Distribution of allele and genotype frequencies of rs5370

\begin{tabular}{|c|c|c|c|c|c|c|c|c|}
\hline \multirow[t]{3}{*}{ Group } & \multicolumn{7}{|c|}{ Single nucleotide polymorphism } & \multirow[t]{3}{*}{$N$} \\
\hline & \multicolumn{3}{|c|}{ Allele frequencies (percent) } & \multicolumn{4}{|c|}{ Genotype frequencies (percent) } & \\
\hline & $\mathrm{T}$ & G & $P$-value & TT & GT & GG & $P$-value & \\
\hline $\begin{array}{l}\text { Hypertensive } \\
(\mathrm{H}+\mathrm{A}+\text { and } \mathrm{H}+\mathrm{A}-)\end{array}$ & $24(9)$ & $122(51)$ & 0.501 & $15(6)$ & $9(3)$ & $113(43)$ & 0.563 & 137 \\
\hline $\begin{array}{l}\text { Non-hypertensive } \\
(\mathrm{H}-\mathrm{A}+\text { and } \mathrm{H}-\mathrm{A}-)\end{array}$ & $25(10)$ & $104(40)$ & & $19(7.5)$ & $6(2.5)$ & $98(38)$ & & 123 \\
\hline $\begin{array}{l}\text { With coronary } \\
\text { atherosclerosis } \\
(\mathrm{H}-\mathrm{A}+\text { and } \mathrm{H}+\mathrm{A}+)\end{array}$ & $37(13)$ & $111(41)$ & 0.003 & $26(9.6)$ & $11(4)$ & $100(38.5)$ & 0.011 & 137 \\
\hline $\begin{array}{l}\text { Without coronary } \\
\text { atherosclerosis } \\
(\mathrm{H}-\mathrm{A}-\text { and } \mathrm{H}+\mathrm{A}-)\end{array}$ & $14(4)$ & $113(42)$ & & $10(4)$ & $4(1.5)$ & $109(42.4)$ & & 123 \\
\hline
\end{tabular}

Values are presented as number (percentage). Significant difference at $<0.05$. The frequency of TT genotype is significantly higher in individuals with coronary atherosclerosis in comparison with those without coronary atherosclerosis $(p=0.011)$. The frequency of the $T$ allele (Asn) is significantly higher in people with coronary atherosclerosis in comparison with those without coronary atherosclerosis $(p=0.003)$. There is no significant difference in allele and genotype frequencies of rs5370 between hypertensive and non-hypertensive individuals ( $p=0.501, p=0.563$ ). $N$-indicates the total population of each section, $H-A--$ no coronary artery disease and no hypertension, $H+A--$ hypertension and no coronary artery disease, $H-A+-$ coronary artery disease and no hypertension, $H+A+-$ coronary artery disease and hypertension. 
Table III. Distribution of allele and genotype frequencies of rs10478694

\begin{tabular}{|c|c|c|c|c|c|c|c|c|}
\hline \multirow[t]{2}{*}{ Group } & \multicolumn{3}{|c|}{ Allele frequencies (\%) } & \multicolumn{4}{|c|}{ Genotype frequencies (\%) } & \multirow[t]{2}{*}{$N$} \\
\hline & $4 \mathrm{~A}$ & $3 A$ & $P$-value & $3 \mathrm{~A} 4 \mathrm{~A}$ & $3 A 3 A$ & $4 \mathrm{~A} 4 \mathrm{~A}$ & $P$-value & \\
\hline $\begin{array}{l}\text { Hypertensive } \\
(\mathrm{H}+\mathrm{A}+\text { and } \mathrm{H}+\mathrm{A}-)\end{array}$ & $82(31)$ & $93(35)$ & 0.004 & $38(15)$ & $55(21)$ & $44(17)$ & 0.007 & 137 \\
\hline $\begin{array}{l}\text { Non-hypertensive } \\
(\mathrm{H}-\mathrm{A}+\text { and } \mathrm{H}-\mathrm{A}-)\end{array}$ & $98(37)$ & $59(22)$ & & $34(13)$ & $25(9.5)$ & $64(24.5)$ & & 123 \\
\hline $\begin{array}{l}\text { With coronary } \\
\text { atherosclerosis } \\
(\mathrm{H}-\mathrm{A}+\text { and } \mathrm{H}+\mathrm{A}+)\end{array}$ & $90(34)$ & $80(30)$ & 0.862 & $33(12.7)$ & $47(18)$ & $57(22.2)$ & 0.241 & 137 \\
\hline $\begin{array}{l}\text { Without coronary } \\
\text { atherosclerosis } \\
(\mathrm{H}-\mathrm{A}-\text { and } \mathrm{H}+\mathrm{A}-)\end{array}$ & $90(34)$ & $73(28)$ & & $40(15.4)$ & $33(12.7)$ & $50(19)$ & & 123 \\
\hline
\end{tabular}

Values are presented as number (percentage). Significant difference at $<0.05$. The frequency of 3A3A genotype is significantly higher in hypertensive individuals in comparison with non-hypertensive ones $(p=0.007)$. The frequency of the $3 A$ allele is significantly higher in hypertensive individuals in comparison with non-hypertensive ones $(p=0.004)$. There is no significant difference in allele and genotype frequencies of rs 10478694 between individuals with coronary atherosclerosis and those without coronary atherosclerosis ( $p=0.862$, $p=0.241$ ). $\mathrm{N}$-indicates the total population of each section, $\mathrm{H}-\mathrm{A}--$ no coronary artery disease and no hypertension, $H+A--$ hypertension and no coronary artery disease, $\mathrm{H}-\mathrm{A}_{+}-$coronary artery disease and no hypertension, $\mathrm{H}+\mathrm{A}+-$ coronary artery disease and hypertension.

eral other studies [7-10]. Although Parinello et al. and Sarafidis and Bakris declared that the association of plasma level of ET-1 with the development of hypertension was dependent on specific conditions such as obesity and insulin resistance $[9,10]$, it has been reported in some studies that obesity can affect expression of some genes and cause metabolic imbalance which can lead to various diseases [42]. In this case there might be no connection between the increasing level of ET-1 in the blood and the development of hypertension; yet, in our study (as the BMI level did not exceed $30 \mathrm{~kg} / \mathrm{m}^{2}$ ) obesity was not considered an influencing factor. Yoshibayashi et al. claimed that the effect of this peptide on the development of essential hypertension is clear due to the higher level of prepro ET-1 mRNA in the serum of people suffering from this disease; however, their serum level of ET-1 has not been reported [7]. Katona's study shows that ET-1 plasma level was not significantly elevated in hypertension patients [43].

The ANCOVA and Tukey tests showed only a significant difference between $\mathrm{H}+\mathrm{A}+$ and $\mathrm{H}+\mathrm{A}-$; therefore, we concluded that ET-1 plasma level may be associated with the development of coronary atherosclerosis. In a healthy vessel, there is an equilibrium between ET-1 activities through ETA and ETB, which will help to maintain the endothelial function. If induced by the specific factors [44], ET-1 upregulation and elevated secretion can affect the endothelial function due to its known effect on the elevation of production of superoxides [36]. By disrupting nitric oxide synthase activity, superoxides can reduce the generation of nitric oxide and therefore its effects on the vascular balance and endothelial function [45, 46]. One of the main consequences of endothelial dysfunction is atherosclerosis [36, 46]. It is mentioned in Kawashima's study that NO acts as an anti-atherosclerotic factor by controlling the vascular tone, preventing monocytes from sticking to the endothelial surface, preventing proliferation and immigration of smooth muscle cells [47].

The analysis of the distribution of rs5370 alleles and genotypes revealed significantly higher frequencies of the TT genotype and T allele (Asn) in people with CA in comparison with those without atherosclerosis $(p=0.011, p<0.001)$. Yet, the present results showed no significant association between rs5370 allele and genotype distribution and the development of hypertension ( $p=0.501$, $p=0.563)$. Some researchers believe that this SNP is not located on a regulatory region of the ET-1 gene and therefore it is unable to have an effect on ET-1 gene expression [19]. According to the significantly higher frequency of Asn (T) and TT genotype in people with atherosclerosis in comparison with those without atherosclerosis (Table II), we concluded that this allele can be regarded as a risk factor causing the development of atherosclerosis.

As shown in Table II, the 3A allele and 3A3A genotype frequencies of $r s 10478694$ were significantly higher in hypertensive individuals ( $p=$ 0.007, $p=0.004$ ). Therefore, it can be deduced that the $3 \mathrm{~A}$ allele and $3 \mathrm{~A} 3 \mathrm{~A}$ genotype of this SNP can be regarded as risk factors that contribute to the development of hypertension. Although these findings are parallel to the findings of other studies [17, 23], some studies have shown contradictory results claiming that this SNP has no association with the development of hypertension $[19,24,25]$. Yet, the $3 \mathrm{~A}$ allele and $3 \mathrm{~A} 3 \mathrm{~A}$ genotype showed no association with the development of atherosclerosis. We found no association between 
ET-1 plasma level and the stage of atherosclerosis (the number of stiffened vessels). We also observed no association between ET-1 plasma level and genotypes in either of the two SNPs.

The strength of this study was the analysis of ET-1 plasma level and its two effective SNPs under different conditions, which revealed some important insights regarding ET-1 in hypertension and CA. However, this study was performed in one center, which may limit the external validity of current findings.

It is suggested to conduct similar studies on other races and populations worldwide to attain a more comprehensive understanding of the association of endothelin- 1 and its polymorphisms with the development of hypertension and CA.

In conclusion, based on the present findings, ET-1 plasma level is positively correlated with the risk of CA development. The $T$ allele can be regarded as a risk factor for CA development. The 3A allele (3A/3A genotype) of rs10478694 may be associated with the risk of hypertension in the south-eastern populations of Iran.

\section{Acknowledgments}

This study was granted by Kerman University of Medical Sciences and is part of an M.Sc. thesis. The authors would like to thank all participants for their help.

\section{Conflict of interest}

The authors declare no conflict of interest.

\section{References}

1. Maguire JJ, Davenport AP. Endothelin receptors and their antagonists. Semin Nephrol 2015; 3: 125-36.

2. Peto $H$, Corder R, Janes RW, Wallace BA. A molecular model for human Big-Endothelin-1 (Big ET-1). FEBS Lett 1996; 394: 191-5.

3. Schiffrin EL. Vascular endothelin in hypertension. Vascul Pharmacol 2005; 43: 19-29.

4. Forouzanfar MH, Liu P, Roth GA, et al. Global burden of hypertension and systolic blood pressure of at least 110 to $115 \mathrm{~mm} \mathrm{Hg}, 1990-2015$. JAMA 2017; 317: 165-82.

5. Pusuroglu H, Akgul O, Erturk M, et al. Red cell distribution width and end-organ damage in patients with systo-diastolic hypertension. Arch Med Sci 2016; 12: 319-25.

6. Kearney PM, Whelton M, Reynolds K, Muntner P, Whelton PK, He J. Global burden of hypertension: analysis of worldwide data. Lancet 2005; 365: 217-23.

7. Yoshibayashi M, Nishioka K, Nakao K, et al. Plasma endothelin concentrations in patients with pulmonary hypertension associated with congenital heart defects. Evidence for increased production of endothelin in pulmonary circulation. Circulation 1991; 84: 2280-5.

8. Ergul S, Parish DC, Puett D, Ergul A. Racial differences in plasma endothelin-1 concentrations in individuals with essential hypertension. Hypertension 1996; 28: 652-5.
9. Parrinello G, Scaglione R, Pinto A, et al. Central obesity and hypertension: the role of plasma endothelin. Am J Hypertension 1996; 9: 1186-91.

10. Sarafidis PA, Bakris GL. Review: insulin and endothelin: an interplay contributing to hypertension development? J Clin Endocrinol Metab 2007; 92: 379-85.

11. Esteghamati A, Abbasi M, Alikhani S. Prevalence, awareness, treatment, and risk factors associated with hypertension in the Iranian population: the national survey of risk factors for noncommunicable diseases of Iran. Am J Hypertens 2008; 21: 620-6.

12. Stewart DJ, Levy RD, Cernacek P, Langleben D. Increased plasma endothelin-1 in pulmonary hypertension: marker or mediator of disease? Ann Intern Med 1991; 114: 464-9.

13. Schiffrin EL. Endothelin: potential role in hypertension and vascular hypertrophy. Hypertension 1995; 25: 1135-43.

14. Jin JJ, Nakura J, Wu Z, et al. Association of endothelin-1 gene variant with hypertension. Hypertension 2003; 41: 163-7.

15. Gene - NCBI. National Center for Biotechnology Information, U.S. National Library of Medicine, www.ncbi. nlm.nih.gov/gene/?term=rs10478694.

16. Uchida Y, Sugiura S, Nakashima T, Ando F, Shimokata H. Endothelin-1 gene polymorphism and hearing impairment in elderly Japanese. Laryngoscope 2009; 119: 938-43.

17. Vadapalli S, Rani HS, Sastry B, Nallari P. Endothelin-1 and endothelial nitric oxide polymorphisms in idiopathic pulmonary arterial hypertension. Int J Mol Epidemiol Genet 2010; 1: 208-13.

18. Tiret L, Poirier O, Hallet V, et al. The Lys198Asn polymorphism in the endothelin-1 gene is associated with blood pressure in overweight people. Hypertension 1999; 33: 1169-74.

19. Ferri C, Bellini C, Desideri G, et al. Plasma endothelin-1 levels in obese hypertensive and normotensive men. Diabetes 1995; 44: 431-6.

20. Fang Z, Li M, Ma Z, Tu G. Association of endothelin-1 gene polymorphisms with essential hypertension in a Chinese population. Genet Mol Res 2017; 16. DOI: 10.4238/gmr16037446.

21. Yang F, Lai X, Deng L, et al. Association of endothelin-1 gene polymorphisms with the clinical phenotype in primary nephrotic syndrome of children. Life Sci 2014; 118: 446-50.

22. Diefenbach K, Arjomand Nahad F, Meisel C, et al. Identification of twelve polymorphisms in the endothelin-1 gene by use of fluorescently labeled oligonucleotides and PCR with restriction fragment polymorphism analysis. Clin Chem 2004; 50: 448-51.

23. Vasku A, Izakovicova Holla L, Tschplova S, Muzik J, Soucek M, Vacha J. An association of three polymorphisms in the gene coding for endothelin-1 (ET-1) in essential hypertension. Atherosclerosis 2000; 151: 255.

24. Ibrahima E, Kassema A, Zakaria N. The role of the biomarker and the genetic polymorphism of endothelin-1 in pulmonary arterial hypertension among Egyptians. Egypt J Chest Dis Tuberc 2012; 61: 495-500.

25. Calabro P, Limongelli G, Maddaloni V, et al. Analysis of endothelin-1 and endothelin-1 receptor A gene polymorphisms in patients with pulmonary arterial hypertension. Intern Emerg Med 2012; 7: 425-30.

26. Lajemi M, Gautier S, Poirier O, et al. Endothelin gene variants and aortic and cardiac structurein never-treated hypertensives. Am J Hypertens 2001; 14: 755-60. 
27. Bousette N, Giaid A. Endothelin-1 in atherosclerosis and other vasculopathies. Can J Physiol Pharmacol 2003; 81: 578-87.

28. Perez HA, Garcia NH, Spence JD, Armando LJ. Adding carotid total plaque area to the Framingham risk score improves cardiovascular risk classification. Arch Med Sci 2016; 12: 513-20.

29. Okuturlar Y, Gedikbasi A, Akalin N, et al. Serum paraoxonase 1 activity in patients with iron deficiency anemia. Arch Med Sci 2016; 12: 697-703.

30. Lerman A, Holmes DR Jr, Bell MR, Garratt KN, Nishimura RA, Burnett JC Jr. Endothelin in coronary endothelial dysfunction and early atherosclerosis in humans. Circulation 1995; 92: 2426-31.

31. Lerman A, Webster MW, Chesebro JH, et al. Circulating and tissue endothelin immunoreactivity in hypercholesterolemic pigs. Circulation 1993; 88: 2923-8.

32. Jesmin S, Zaedi S, Maeda S, et al. Endothelin antagonism suppresses plasma and cardiac endothelin-1 levels in SHRSPs at the typical hypertensive stage. Exp Biol Med 2006; 231: 919-24.

33. McCarter SD, Lai PF, Suen RS, Stewart DJ. Regulation of endothelin-1 by angiopoietin-1: implications for inflammation. Exp Biol Med 2006; 231: 985-91.

34. Liu H, Peng Y, Liu F, et al. Correlation between endothelin-1 and atherosclerosis in chronic hemodialysis patients. J Nephrol 2010; 23: 593-602.

35. Erdem F, Cakır U, Yıldırım O, et al. A new diagnostic tool for masked hypertension: impaired sleep quality. Arch Med Sci 2016; 12: 1207-13.

36. Panoulas VF, Douglas KM, Smith JP, et al. Polymorphisms of the endothelin-1 gene associate with hypertension in patients with rheumatoid arthritis. Endothelium 2008; 15: 203-12.

37. Rajzer M, Wojciechowska W, Kameczura T, Olszanecka A. The effect of antihypertensive treatment on arterial stiffness and serum concentration of selected matrix metalloproteinases. Arch Med Sci 2017; 13: 760-70.

38. Swarowska M, Burkot J, Janowska A, et al. Improvement of survival in Polish stroke patients is related to reduced stroke severity and better control of risk factors: the Krakow Stroke Database. Arch Med Sci 2016; 12: 552-55.

39. Raff GL, Gallagher MJ, O'Neill WW, Goldstein JA. Diagnostic accuracy of noninvasive coronary angiography using 64-slice spiral computed tomography. J Am Coll Cardiol 2005; 46: 552-7.

40. Ali SM, Mahnaz S, Mahmood T. Rapid genomic DNA extraction (RGDE). Forensic Sci Int Genet Suppl Ser 2008; 1: 69-75.

41. Thakur TJ, Guindo A, Cullifer LR, et al. Endothelin-1 but not endothelial nitric oxide synthase gene polymorphism is associated with sickle cell disease in Africa. Gene Regul Syst Bio 2014; 8: 119-26.

42. Ulloa-Martínez M, Burguete-García Al, Murugesan S, Hoyo-Vadillo C, Cruz-Lopez M, García-Mena J. Expression of candidate genes associated with obesity in peripheral white blood cells of Mexican children. Arch Med Sci 2016; 12: 969-76.

43. Katona E, Settakis G, Varga Z, et al. Target-organ damage in adolescent hypertension. Analysis of potential influencing factors, especially nitric oxide and endothelin-1. J Neurol Sci 2006; 247: 138-43.

44. Böhm F, Pernow J. The importance of endothelin-1 for vascular dysfunction in cardiovascular disease. Cardiovasc Res 2007; 76: 8-18.

45. Rapoport RM. Nitric oxide inhibition of endothelin-1 release in the vasculature: in vivo relevance of in vitro findings. Hypertension 2014; 64: 908-14.
46. Wu Y, Duan S, Qiang X, Ning Z, Xing C, Zhang B. Sympathetic renal denervation in hypertension with chronic kidney disease: a case report and review of literature. Int J Clin Exp Med 2015; 8: 16858-62.

47. Kawashima S. Malfunction of vascular control in lifestyle-related diseases: endothelial nitric oxide (NO) synthase/NO system in atherosclerosis. J Pharmacol Sci 2004; 96: 411-9. 